\title{
BDNF-dependent consolidation of fear memories in the perirhinal cortex
}

\author{
Brigitte Schulz-Klaus ${ }^{1}$, Volkmar Lessmann ${ }^{2,3}$ and Thomas Endres ${ }^{2 *}$ \\ 1 Tierphysiologie, Institut für Neurobiologie, Universität Tübingen, Tübingen, Germany \\ ${ }^{2}$ Medizinische Fakultät, Institut für Physiologie, Otto-von-Guericke Universität Magdeburg, Magdeburg, Germany \\ ${ }^{3}$ Center for Behavioral Brain Research (CBBS), Otto-von-Guericke Universität Magdeburg, Magdeburg, Germany
}

Edited by:

Katharina A. Braun, Otto-von-Guericke University, Germany

\section{Reviewed by:}

Clive R. Bramham, University of

Bergen, Norway

Jonathan L. C. Lee, Birmingham

University, UK

*Correspondence:

Thomas Endres, Faculty of Medicine,

Institute of Physiology,

Otto-von-Guericke-University

Magdeburg, Leipziger Street 44,

39120 Magdeburg, Germany

e-mail: thomas.endres@med.ovgu.de
In the recent years the perirhinal cortex (PRh) has been identified as a crucial brain area in fear learning. Since the neurotrophin brain-derived neurotrophic factor (BDNF) is an important mediator of synaptic plasticity and also crucially involved in memory consolidation of several learning paradigms, we analyzed now whether fear conditioning influences the expression of BDNF protein in the PRh. Here we observed a specific increase of BDNF protein 120 min after fear conditioning training. In order to test whether this increase of BDNF protein level is also required for the consolidation of the fear memory, we locally applied the Trk receptor inhibitor k252a into the PRh during this time window in a second series of experiments. By interfering with Trk-signaling during this critical time window, the formation of a long-term fear memory was completely blocked, indicated by a complete lack of fear potentiated startle 1 day later. In conclusion the present study further emphasizes the important role of the PRh in cued fear learning and identified BDNF as an important mediator for fear memory consolidation in the PRh.

Keywords: perirhinal cortex, brain-derived neurotrophic factor, fear potentiated startle, fear learning, consolidation

\section{INTRODUCTION}

Fear learning is a very efficient and evolutionarily highly beneficial learning mechanism that increases the survival probability of an individual in dangerous situations (e.g., Maren, 2001; Pape and Pare, 2010). On the other hand dysfunctions in fear learning are supposed to be one of the major causes for the development of several anxiety disorders, like PTSD (see e.g., Koenigs and Grafman, 2009; Jovanovic and Ressler, 2010; Mahan and Ressler, 2012). Thus the understanding of the underlying neuronal mechanisms and circuitries might lead to novel treatment strategies for several anxiety disorders.

The key brain area mediating cued fear learning in higher vertebrates is the amygdala complex (Maren, 2001; Fanselow and Gale, 2003; LeDoux, 2007; Pape and Pare, 2010). Chronic and temporary lesions of the lateral/basolateral complex of the amygdala block the acquisition, consolidation and expression of fear (e.g., Johansen et al., 2011; Sierra-Mercado et al., 2011). In addition, fear learning alters synaptic plasticity in this area (e.g., Rogan et al., 1997; Sigurdsson et al., 2007). Besides the amygdala, other brain areas have also been identified to be crucially involved in cued fear learning. Among these areas are the prelimbic ventromedial prefrontal cortex (PL; e.g., BurgosRobles et al., 2009; Choi et al., 2010; Sierra-Mercado et al., 2011) and the perirhinal cortex (PRh; e.g., Schulz et al., 2004; Furtak et al., 2007; Kealy and Commins, 2011; Kent and Brown, 2012). Interestingly, the PRh has strong reciprocal projections to many brain areas that are linked to emotional learning and fear conditioning in particular, like the amygdala (e.g., Pikkarainen and Pitkanen, 2001), the medioprefrontal cortex (e.g., Heidbreder and Groenewegen, 2003), the thalamus (e.g., McIntyre et al., 1996) and the hippocampus (e.g., Kloosterman et al., 2003), thus making the PRh an important part in the neuronal circuitry mediating the formation of fear memories. However, the concrete involvement of PRh in fear learning as well as the underlying neuronal processes is still not fully understood (compare e.g., Kealy and Commins, 2011).

The neurotrophin brain-derived neurotrophic factor (BDNF) is an important mediator for synaptic plasticity and memory formation, acting via activation of TrkB (tropomyosin-related kinase B) receptors (Bekinschtein et al., 2008; Gottmann et al., 2009; Cowansage et al., 2010). Several recent studies demonstrated also an important role of BDNF in synaptic plasticity in the amygdala (i.e., long-term potentiation: Musumeci et al., 2009; Meis et al., 2012) as well as for cued fear learning (Rattiner et al., 2004a,b, 2005; Ou and Gean, 2006; Jones et al., 2007; Ou et al., 2010; Andero et al., 2011; Endres and Lessmann, 2012; Psotta et al., 2013). In addition, for proper consolidation of fear memories BDNF-TrkB-signaling is also required in the PL (Choi et al., 2010). In the PRh, BDNF has so far been shown to be important for object recognition memory (Hopkins and Bucci, 2010; Munoz et al., 2010; Hopkins et al., 2011; Callaghan and Kelly, 2012). Since the $\mathrm{PRh}$ is supposed to be involved in the consolidation of both contextual and cued fear memories (Suzuki, 1996; Sacchetti et al., 1999; Burwell et al., 2004), it seems reasonable to assume that BDNF signaling in the PRh might be involved in the consolidation processes of fear memories. However, this issue has not been 
analyzed so far. Therefore, we analyzed in the present study, whether BDNF in the PRh is required for cued fear learning. In order to test this, we first applied a fear conditioning paradigm that has been shown to rely on PRh function (Schulz et al., 2004) and looked for the expression of BDNF-protein in the PRh upon fear learning. Therefore, we analyzed the amount of BDNF protein in the PRh at distinct time points after fear conditioning training by using a sensitive BDNF-ELISA. Here we observed a strong increase in BDNF protein 120 min after fear conditioning training. In a second series of experiments, we locally injected the unspecific tyrosine kinase inhibitor k252a at the time point matching the peak of BDNF protein expression in the PRh to inhibit TrkB kinases. The fear memory of the animals was assessed by applying the fear potentiated startle paradigm (Davis et al., 1993; Fendt and Fanselow, 1999; Fendt and Koch, 2013). Here we observed complete inhibition of the formation of fear memories, indicated by the absence of fear potentiated startle. In conclusion these results suggest that BDNF signaling in the PRh is required for the successful consolidation of fear memories. However, the involvement of other tyrosine kinases also affected by $\mathrm{k} 252 \mathrm{a}$ (i.e., TrkA, TrkC) cannot be excluded.

\section{MATERIALS AND METHODS \\ ANIMALS}

For the present study 56 male adult (220-320 g) Sprague-Dawley rats (Charles River, Sulzfeld, Germany) were used. They were housed in groups of 4-6 animals under a $12 \mathrm{~h} / 12 \mathrm{~h}$ light dark cycle (lights on at 7:00 a.m.) and had free accesses to food and water. All experiments were performed in accordance with the ethical guidelines for care and usage of laboratory animals and were approved by the local animal care committee (Regierungspräsidium Tübingen: ZP 3/06).

\section{SURGERY}

Rats were deeply anesthetized with ketamine/xylazine (9:1, $100 \mathrm{mg} / \mathrm{kg}$ bodyweight) and fixed into a stereotaxic device. Under stereotaxic control two cannulas $(0.7 \mathrm{~mm}$ in diameter $)$ were implanted bilaterally into the brain, aiming at the PRh $(+2.6 \mathrm{~mm}$ caudal, $\pm 6.2 \mathrm{~mm}$ lateral and $7.6 \mathrm{~mm}$ ventral in relation to Bregma (coordinates according to Paxinos and Watson, 1997)). The cannulas were fixed with dental cement and three anchoring screws on the skull bone. After surgery the rats were allowed at least 7 days to fully recover before the behavioral testing started.

\section{FEAR CONDITIONING}

For fear conditioning two identical dark boxes $(38 \times 60 \times$ $28 \mathrm{~cm}^{3}$ ) were used. A $15 \mathrm{~W}$ white light served as the conditioned stimulus (CS) that was paired with a $0.5 \mathrm{~s}$ lasting $0.6 \mathrm{~mA}$ foot shock, which served as unconditioned stimulus (US). Initially the animals received $5 \mathrm{~min}$ to adapt to the conditioning chamber and then received $10 \mathrm{CS}$-US pairings with variable inter-trial intervals (1-3 $\mathrm{min})$. The US presentation $(0.5 \mathrm{~s})$ always co-terminated with the light presentation (3.7 s). As control group for the BDNFprotein quantification, a group of animals was pseudo conditioned by receiving the same number of CS und US presentations, but in an unpaired manner.

\section{INTRACRANIAL INJECTIONS}

The rats received microinjections of either $\mathrm{k} 252 \mathrm{a}(150 \mu \mathrm{M}, 0.3 \mu \mathrm{l}$ per side, Alomone labs, Israel) dissolved in DMSO (SigmaAldrich, Germany) or DMSO as control via injection cannulas (0.4 $\mathrm{mm}$ in diameter) directly into the PRh. The drugs were infused bilaterally with a velocity of $0.1 \mu \mathrm{l} / 10 \mathrm{~s}$. The cannulas were left in place for additional $2 \mathrm{~min}$ in order to allow diffusion into the surrounding tissue. Since $\mathrm{k} 252 \mathrm{a}$ is supposed to require approximately $30 \mathrm{~min}$ to attain its full inhibitory effect on Trk receptors (compare e.g., Ou et al., 2010), the drugs were infused 90 min after the fear conditioning training has ended, to block Trk activity at $120 \mathrm{~min}$ when we observed the maximum increase in BDNF protein in the PRh (compare Figure 1).

\section{FEAR POTENTIATED STARTLE}

The setup to measure the startle amplitudes was located in a sound attenuating test chamber $\left(100 \times 80 \times 60 \mathrm{~cm}^{3}\right)$. The rats were placed in wire mesh cages $\left(20 \times 10 \times 12 \mathrm{~cm}^{3}\right)$ that were mounted on a piezoelectric accelerometer (custommade at the University of Tübingen). All movements of the rats resulted in voltage output changes, which were amplified, digitized and analyzed by a computer. The whole body acoustic startle response (ASR) amplitude was calculated as the peak-topeak voltage outputs of the accelerometer. A loudspeaker located $40 \mathrm{~cm}$ away from the test cages presented the startle stimuli and a continuous white background noise (52 dB SPL). The presentation of the acoustic startle stimuli was controlled by a computer and a DA-interface (Hortmann universal function synthesizer, Hortmann, Neckartenzlingen, Germany). The startle stimuli were $20 \mathrm{~ms}$ tone pulses $(10 \mathrm{kHz}, 100 \mathrm{~dB}$ SPL) including

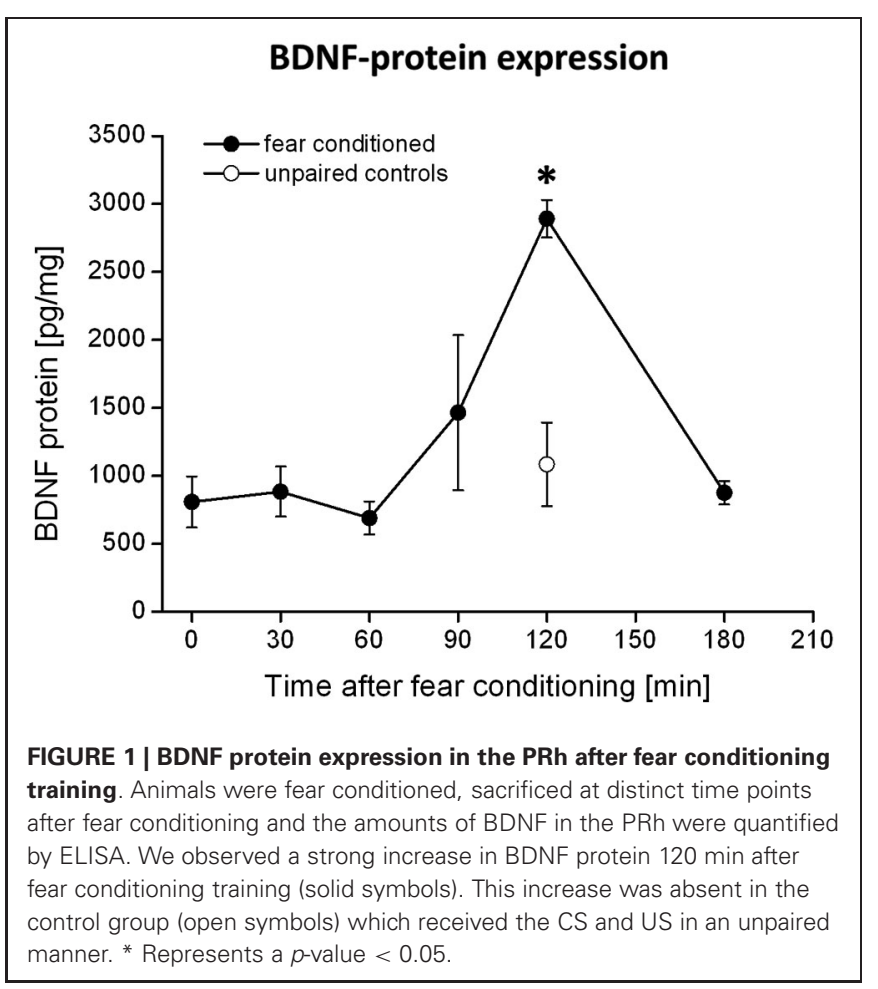


$0.4 \mathrm{~ms}$ rise and fall times, which were presented with a fixed interstimulus interval of $30 \mathrm{~s}$. At the beginning of the test, the rats were allowed $5 \mathrm{~min}$ time to acclimatize to the test chamber. Then 10 initial startle trials were presented to the animals to induce a stable baseline of ASR magnitude. Afterwards the animals were exposed to 20 startle stimuli. Half of these stimuli were presented $3.2 \mathrm{~s}$ after the onset of the light CS (light-tone trials), whereas the other half were presented in the absence of the CS (tone alone trials). The two trial types were presented in a pseudo-randomized manner. The difference between the tone alone and the light-tone trials was used as an operational measure of fear (e.g., Davis et al., 1993; Fendt and Fanselow, 1999). The fear potentiation was calculated as the mean relative increase in startle amplitude by the CS presentation compared to the tone-alone trials. Therefore, we set the mean startle amplitude during the tone-alone trials to $100 \%$ and calculated the relative change of the mean startle amplitude during the light-tone trials. This fear potentiation was calculated for each animal individually and then averaged for the respective groups (see also methods in Walker et al., 2009). The fear potentiated startle test was performed $24 \mathrm{~h}$ after the fear conditioning training.

\section{HISTOLOGY}

After the behavioral tests were finished, the rats were killed with an overdose of pentobarbital. The brains were removed and fixed with $8 \%$ paraformaldehyde in PBS with 20\% sucrose. Coronal sections $(60 \mu \mathrm{m})$ were taken using a freezing microtome and nissel stained. Correct placements of cannulas were verified by analyzing the stained brain slices under a light microscope. The positions of the cannulas are depicted in Figure 2.

\section{BDNF PROTEIN QUANTIFICATION}

A separate group of 28 animals were fear conditioned with the identical fear conditioning protocol as used for the fear potentiated startle experiments (see above). As control a group of animals received a pseudo conditioning, i.e., an identical number of light stimuli and foot shocks that were presented in an unpaired manner to these animals. For each time point we used a group of four animals. At different time points after the fear conditioning $(0,30,60,90,120$ and $180 \mathrm{~min})$ the animals were sacrificed and the removed brains were dissected similar to the rapid brain dissection method described by (Heffner et al., 1980). After the PRh was excised it was immediately shock-frozen with liquid nitrogen and afterwards stored at $-80^{\circ} \mathrm{C}$ till further processing. The amount of BDNF protein in the samples was determined by using the Quantikine BDNF ELISA-kit (R\&DSystems, Wiesbaden, Germany). The tissue samples were processed according to the kit instructions.

\section{STATISTICAL ANALYSIS}

All data were analyzed either by using analysis of variance (ANOVA) tests followed by planned post-hoc $t$-test comparisons (alpha set at 0.05). All calculations were performed by using JMP (SAS Institute Inc., Version 8 ) software. A $p$-value $<0.05$ was set as level of significance.

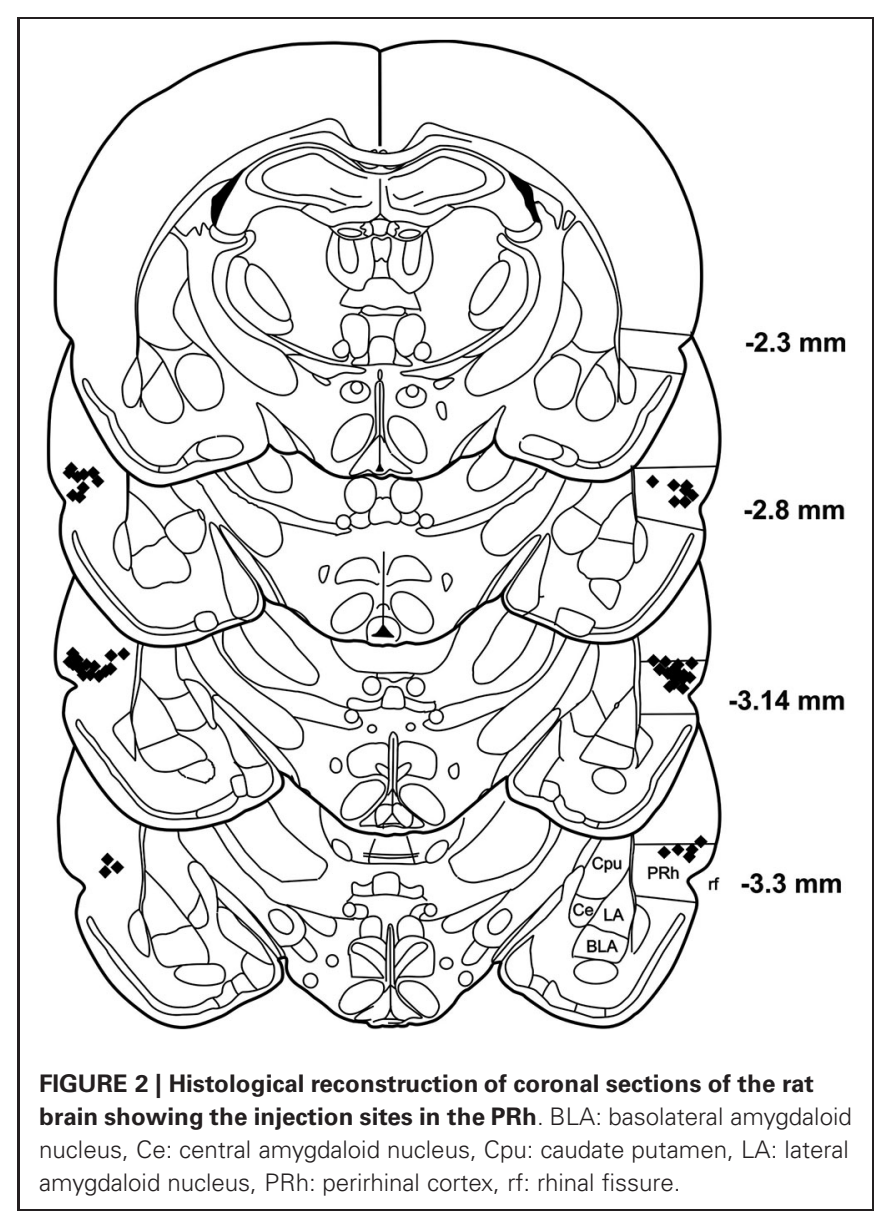

\section{RESULTS \\ BDNF EXPRESSION IN THE PERIRHINAL CORTEX AFTER FEAR CONDITIONING}

Quantification of BDNF levels in the PRh at different time points after fear conditioning by means of BDNF-ELISA revealed a strong increase in BDNF protein at 120 min after fear conditioning training (compare Figure 1). This observation is supported by an ANOVA showing a significant effect of BDNF expression between the different time points $\left(F_{5,27}=2.8\right.$; $\left.p=0.04\right)$. Posthoc Tukey comparisons revealed significant differences between BDNF levels at $120 \mathrm{~min}$ and all other time points, except for the $90 \mathrm{~min}$ time point. However, the increase in BDNF protein at $90 \mathrm{~min}$ is only due to a very high amount of BDNF protein measured in the PRh of one animal, whereas all other samples were in a similar range (i.e., around $800 \mathrm{pg} / \mathrm{mg}$ ) as those measured at other time points (i.e., 0-60 $\mathrm{min}$ ). As a control, we analyzed the amount of BDNF protein in the PRh of pseudoconditioned animals at the time of the maximum BDNF proteinexpression, i.e., $120 \mathrm{~min}$ after fear conditioning. Here we observed no altered BDNF expression compared to time point 0 in the fear conditioned group $(p=0.87)$ but a significant difference to time point $120 \mathrm{~min}$ in the fear conditioned group ( $p=0.003$, Bonferroniadapted $t$-test comparisons). Thus, the observed increase in BDNF protein 120 min after fear conditioning seems to be specific for fear learning. 


\section{ACUTE INTERFERENCE WITH BDNF-TrkB-SIGNALING IN THE PERIRHINAL CORTEX}

According to the known pharmacokinetic properties of $\mathrm{k} 252 \mathrm{a}$ after injection into the brain in vivo (compare e.g., Ou et al., 2010), the injection of the tyrosine kinase inhibitor $\mathrm{k} 252 \mathrm{a}$ into the PRh 90 min after fear conditioning was exactly matched to coincide with the maximum BDNF protein expression in this area (compare Figure 1). We observed a complete inhibition of the formation of fear memory, as indicated by a complete lack of fear potentiated startle (Figures 3A, B). We analyzed the changes in the startle amplitudes (Figure $3 \mathbf{A}$ ) by an ANOVA using the factor "treatment" (DMSO vs. k252a) as between subject factor and the factor "phase" (tone alone vs. light-tone) as within subject factor and the interaction of these two factors. This ANOVA revealed a significant effect of the factor "phase" $\left(F_{1,17}=4.95, p=0.039\right)$ but no general treatment effect $\left(F_{1,17}=0.15, p=0.69\right)$. But most importantly there was a significant interaction between these two factors (phase $\times$ treatment: $F_{1,17}=4.71, p=0.04$ ). Post-hoc Bonferroniadapted $t$-test comparisons revealed a significant increase in startle amplitude upon presentation of the CS in DMSO treated animals $(p=0.02)$, whereas there was no significant increase in k252a treated animals. Furthermore, it did not reveal significant differences between $\mathrm{k} 252 \mathrm{a}$ and DMSO treated animals within the tone or light-tone trials. This lack of a significant effect in the light-tone trials might be due to high inter-individual difference in absolute startle amplitudes. In order to get rid of possible effects of inter-individual differences in the absolute startle amplitudes, we also calculated the fear potentiation of the startle amplitude upon CS presentation (Figure 3B). Here we observed a significant higher fear potentiation in DMSO treated animals compared to $\mathrm{k} 252 \mathrm{a}$ treated animals $(p=0.04$, $t$-test comparison).

\section{DISCUSSION}

In the present study, we demonstrate a learning-induced specific increase of BDNF protein in the PRh $120 \mathrm{~min}$ after cued fear conditioning. Furthermore, interfering with BDNF signaling in the PRh during this time window impairs the formation of fear memories, not excluding that other kinases, which are also inhibited by $\mathrm{k} 252 \mathrm{a}$ might contribute to this effect.

By analyzing the levels of BDNF protein at different time points after fear conditioning training, we observed a strong increase of BDNF $120 \mathrm{~min}$ after fear conditioning took place. Since we observed this increase at $120 \mathrm{~min}$ only in the fear conditioned but not in the unpaired control animals, it can be ruled out that this increase of BDNF is due to the shock administration itself. A specific increase of BDNF protein upon cued fear learning has previously been demonstrated for the amygdala (Ou and Gean, 2006; Ou et al., 2010): here the BDNF protein increases 1 and $12 \mathrm{~h}$ after fear conditioning training. In addition, these authors showed that interfering with BDNF-TrkBsignaling at these time points prevent the consolidation of fear memory. Also for other learning tasks, like inhibitory avoidance learning, an increase in BDNF protein at distinct time points after the learning task has been described (Bekinschtein et al., 2007). Interestingly, the expression profiles of BDNF in the PRh and the amygdala seem to follow different time courses during fear learning, suggesting that BDNF-dependent consolidation processes in fear learning are not a unique and stereotypic process across different brain areas. The ELISA cannot distinguish between the pro and mature forms of BDNF. It has been shown that the

\section{Fear potentiated startle}

A Startle amplitudes

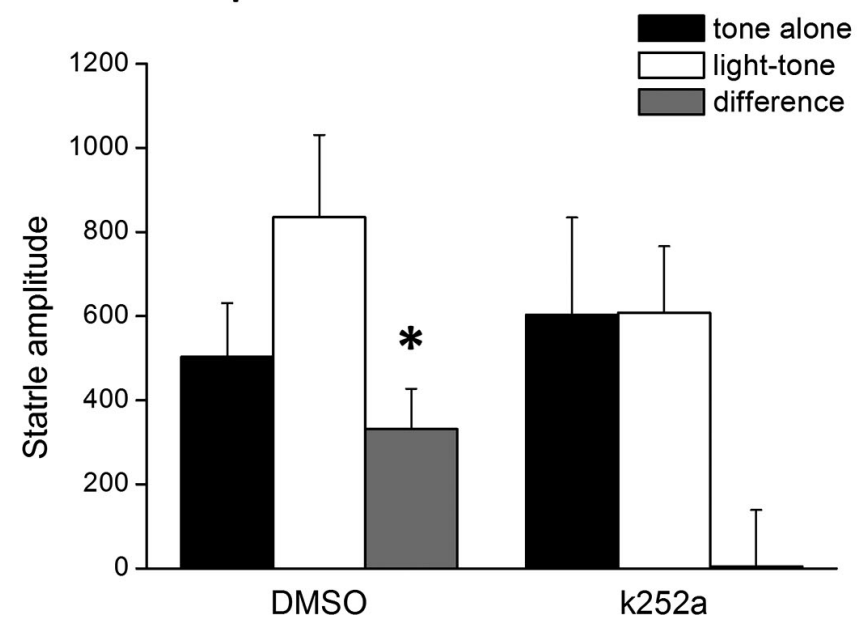

B Fear potentiation

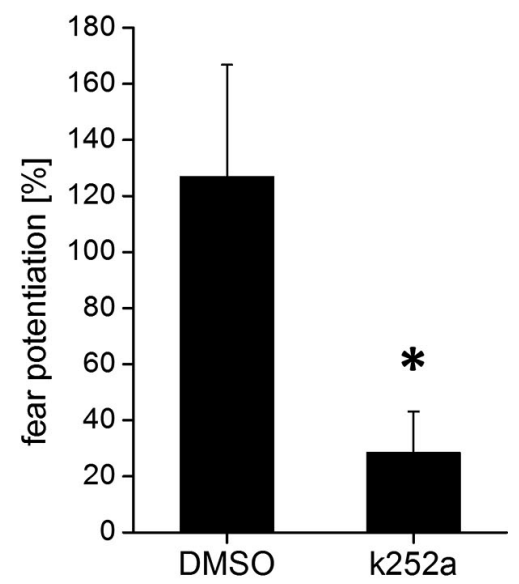

FIGURE 3 | Blocking Trk activity 120 min after fear conditioning by local k252a application impairs fear potentiation of the acoustic startle response $\mathbf{2 4} \mathbf{h}$ after fear conditioning training. (A) Mean ASR amplitude after tone-alone and light-tone trials, as well the difference scores (+SEM). (B) Relative fear potentiation of the startle amplitude by the presentation of the CS. * Represents a $p$-value $<0.05$. 
processing from pro to mature BDNF is required for the induction and maintenance of LTP (e.g., Pang et al., 2004) as well as for cued and contextual fear learning (Barnes and Thomas, 2008; Wetsel et al., 2013). Interestingly both isoforms seem to have opposing effects on fear memory in that way that increased levels of mature BDNF seem to be required for the consolidation of fear memories, whereas increased levels of pro-BDNF seem to facilitate the consolidation of fear extinction (Barnes and Thomas, 2008). Given that mature BDNF has been described to be the by far dominant type of BDNF in intact mouse tissue (Matsumoto et al., 2008), it seems likely that mature BDNF is also predominantly detected and observed to be increased in our experiments.

By interfering with tyrosine kinase activity during the time of increased BDNF expression, by local application of the Trkinhibitor k252a, we observed a complete lack of fear memory measured as fear potentiated startle. Although k252a is an unspecific tyrosine kinase inhibitor, under conditions used in our experiments it is a widely accepted tool to analyze the effects of BDNF-TrkB-signaling in vivo (compare Ou and Gean, 2006; Ou et al., 2010; Li et al., 2011; Suzuki et al., 2012; Koike et al., 2013). Given, in addition, the strong increase of BDNF-protein during this identical time window, the observed deficit in fear memory consolidation might be due to a hampered BDNFsignaling via $\mathrm{TrkB}$ receptors. But to finally proof the involvement of TrkB signaling in fear memory consolidation, further studies are needed that analyze either the phosphorylation of the TrkB receptors or apply the more specific BDNF scavenger TrkB-Fc into the PRh during the critical time window after fear conditioning. Nevertheless, our results provide further evidence, that PRh is not only involved in the acquisition and/or expression (Campeau and Davis, 1995; Otto et al., 2000; Schulz et al., 2004) but also in the consolidation of cued fear memories as previously described by (Sacchetti et al., 1999). Furthermore, according to our present data, BDNF seems to play an important role in the PRh enabling proper consolidation of cued fear memories.

It should be noted, that in relation to the used experimental paradigms different contributions of the $\mathrm{PRh}$ in fear learning have been described. So it has been shown that lesions of the PRh disrupted fear conditioning to complex, discontinuous tones or ultrasonic vocalization (e.g., $22 \mathrm{kHz}$ calls) but not to simple, continuous tone stimuli (Lindquist et al., 2004; Furtak et al., 2007; Kholodar-Smith et al., 2008; Bang and Brown, 2009), suggesting that one of the mnemonic PRh functions in fear learning might be the stimulus unitization of complex auditory stimuli (Kent and Brown, 2012). However, in contrast to simple tone stimuli other simple stimuli of other sensory modalities (i.e., a light or an odor) seem to relay on proper PRh function (Campeau and Davis, 1995; Otto et al., 2000; Schulz et al., 2004). Interestingly, all studies using light stimuli as a CS measured fear learning by startle potentiation (Campeau and Davis, 1995; Schulz et al., 2004), whereas studies using acoustic stimuli as CS applied conditioned freezing (e.g., Bang and Brown, 2009). Thus it might be possible that the contribution of the PRh in fear learning could differ between different experimental approaches for assessing fear learning (i.e., conditioned freezing and fear potentiated startle). On the other hand the PRh has been shown to be required to learn a simple odor stimulus as CS in a conditioned freezing paradigm (Herzog and Otto, 1997, 1998). However, to finally resolve this issue, further experiments are required that should analyze whether the PRh is also required for conditioned freezing in response to a conditioned light stimulus. Furthermore, also the functional role of the PRh in the fear memory circuitry remains an open question. So the PRh could serve as a multimodal relay station for sensory inputs to the lateral amygdala, or it serves as an associative brain area that is directly involved in forming the CSUS association (compare also discussions in Campeau and Davis, 1995; Otto et al., 2000).

In conclusion, the present study further emphasizes the important role of PRh in the consolidation of cued fear memories. We could clearly demonstrate that fear conditioning induces a strong and specific increase in BDNF protein 120 min after fear conditioning. Furthermore, if we interfered with Trk-signaling during this critical time window, the formation of fear memories was completely blocked, as indicated by a lack of fear potentiated startle, thus suggesting an important function of BDNF in the PRh during the consolidation of fear memories.

\section{AUTHOR CONTRIBUTION}

Brigitte Schulz-Klaus and Thomas Endres designed the study and performed the experiments. The manuscript was written by Thomas Endres and Brigitte Schulz-Klaus, with assistance of Volkmar Lessmann.

\section{ACKNOWLEDGMENTS}

The authors would like to thank Markus Fendt for fruitful discussions as well as Margit Schmidt, Angela Jahn and Evelyn Friedl for excellent technical support. This work was supported by the Deutsche Forschungsgemeinschaft (DFG, Schu 2338/1-1 to Brigitte Schulz-Klaus and SFB 779, B6 to Volkmar Lessmann).

\section{REFERENCES}

Andero, R., Heldt, S. A., Ye, K., Liu, X., Armario, A., and Ressler, K. J. (2011). Effect of 7,8-Dihydroxyflavone, a small-molecule TrkB agonist, on emotional learning. Am. J. Psychiatry 168, 163-172. doi: 10.1176/appi.ajp.2010.10030326

Bang, S. J., and Brown, T. H. (2009). Perirhinal cortex supports acquired fear of auditory objects. Neurobiol. Learn. Mem. 92, 53-62. doi: 10.1016/j.nlm.2009.01. 002

Barnes, P., and Thomas, K. L. (2008). Proteolysis of proBDNF is a key regulator in the formation of memory. PLoS One 3:e3248. doi: 10.1371/journal.pone. 0003248

Bekinschtein, P., Cammarota, M., Igaz, L. M., Bevilaqua, L. R. M., Izquierdo, I., and Medina, J. H. (2007). Persistence of long-term memory storage requires a late protein synthesis- and BDNF-dependent phase in the hippocampus. Neuron 53, 261-277. doi: 10.1016/j.neuron.2006.11.025

Bekinschtein, P., Cammarota, M., Izquierdo, I., and Medina, J. H. (2008). BDNF and memory formation and storage. Neuroscientist 14, 147-156. doi: 10. $1177 / 1073858407305850$

Burgos-Robles, A., Vidal-Gonzalez, I., and Quirk, G. J. (2009). Sustained conditioned responses in prelimbic prefrontal neurons are correlated with fear expression and extinction failure. J. Neurosci. 29, 8474-8482. doi: 10.1523/jneurosci. 0378-09.2009

Burwell, R. D., Bucci, D. J., Sanborn, M. R., and Jutras, M. J. (2004). Perirhinal and postrhinal contributions to remote memory for context. J. Neurosci. 24, 1102311028. doi: 10.1523/jneurosci.3781-04.2004

Callaghan, C. K., and Kelly, A. M. (2012). Differential BDNF signaling in dentate gyrus and perirhinal cortex during consolidation of recognition memory in the rat. Hippocampus 22, 2127-2135. doi: 10.1002/hipo.22033

Campeau, S., and Davis, M. (1995). Involvement of subcortical and cortical afferents to the lateral nucleus of the amygdala in fear conditioning measured 
with fear-potentiated startle in rats trained concurrently with auditory and visual conditioned stimuli. J. Neurosci. 15, 2312-2327.

Choi, D. C., Maguschak, K. A., Ye, K., Jang, S. W., Myers, K. M., and Ressler, K. J. (2010). Prelimbic cortical BDNF is required for memory of learned fear but not extinction or innate fear. Proc. Natl. Acad. Sci. U S A 107, 2675-2680. doi: 10. 1073/pnas.0909359107

Cowansage, K. K., Ledoux, J. E., and Monfils, M. H. (2010). Brain-derived neurotrophic factor: a dynamic gatekeeper of neural plasticity. Curr. Mol. Pharmacol. 3, 12-29. doi: 10.2174/1874467211003010012

Davis, M., Falls, W. A., Campeau, S., and Kim, M. (1993). Fear-potentiated startle: a neural and pharmacological analysis. Behav. Brain Res. 58, 175-198. doi: 10. 1016/0166-4328(93)90102-v

Endres, T., and Lessmann, V. (2012). Age-dependent deficits in fear learning in heterozygous BDNF knock-out mice. Learn. Mem. 19, 561-570. doi: 10.1101/lm. 028068.112

Fanselow, M. S., and Gale, G. D. (2003). The amygdala, fear and memory. Ann. N Y Acad. Sci. 985, 125-134. doi: 10.1111/j.1749-6632.2003.tb07077.x

Fendt, M., and Fanselow, M. S. (1999). The neuroanatomical and neurochemical basis of conditioned fear. Neurosci. Biobehav. Rev. 23, 743-760. doi: 10. 1016/s0149-7634(99)00016-0

Fendt, M., and Koch, M. (2013). Translational value of startle modulations. Cell Tissue Res. 354, 287-295. doi: 10.1007/s00441-013-1599-5

Furtak, S. C., Allen, T. A., and Brown, T. H. (2007). Single-unit firing in rat perirhinal cortex caused by fear conditioning to arbitrary and ecological stimuli. J. Neurosci. 27, 12277-12291. doi: 10.1523/jneurosci.1653-07.2007

Gottmann, K., Mittmann, T., and Lessmann, V. (2009). BDNF signaling in the formation, maturation and plasticity of glutamatergic and GABAergic synapses. Exp. Brain Res. 199, 203-234. doi: 10.1007/s00221-009-1994-z

Heffner, T. G., Hartman, J. A., and Seiden, L. S. (1980). A rapid method for the regional dissection of the rat brain. Pharmacol. Biochem. Behav. 13, 453-456. doi: 10.1016/0091-3057(80)90254-3

Heidbreder, C. A., and Groenewegen, H. J. (2003). The medial prefrontal cortex in the rat: evidence for a dorso-ventral distinction based upon functional and anatomical characteristics. Neurosci. Biobehav. Rev. 27, 555-579. doi: 10.1016/j. neubiorev.2003.09.003

Herzog, C., and Otto, T. (1997). Odor-guided fear conditioning in rats: 2. Lesions of the anterior perirhinal cortex disrupt fear conditioned to the explicit conditioned stimulus but not to the training context. Behav. Neurosci. 111, 1265-1272. doi: $10.1037 / / 0735-7044.111 .6 .1265$

Herzog, C., and Otto, T. (1998). Contributions of anterior perirhinal cortex to olfactory and contextual fear conditioning. Neuroreport 9, 1855-1859. doi: 10. 1097/00001756-199806010-00035

Hopkins, M. E., and Bucci, D. J. (2010). BDNF expression in perirhinal cortex is associated with exercise-induced improvement in object recognition memory. Neurobiol. Learn. Mem. 94, 278-284. doi: 10.1016/j.nlm.2010.06.006

Hopkins, M. E., Nitecki, R., and Bucci, D. J. (2011). Physical exercise during adolescence versus adulthood: differential effects on object recognition memory and brain-derived neurotrophic factor levels. Neuroscience 194, 84-94. doi: 10. 1016/j.neuroscience.2011.07.071

Johansen, J. P., Cain, C. K., Ostroff, L. E., and Ledoux, J. E. (2011). Molecular mechanisms of fear learning and memory. Cell 147, 509-524. doi: 10.1016/j.cell. 2011.10.009

Jones, S. V., Stanek-Rattiner, L., Davis, M., and Ressler, K. J. (2007). Differential regional expression of brain-derived neurotrophic factor following olfactory fear learning. Learn. Mem. 14, 816-820. doi: 10.1101/lm.781507

Jovanovic, T., and Ressler, K. J. (2010). How the neurocircuitry and genetics of fear inhibition may inform our understanding of PTSD. Am. J. Psychiatry 167, 648662. doi: 10.1176/appi.ajp.2009.09071074

Kealy, J., and Commins, S. (2011). The rat perirhinal cortex: a review of anatomy, physiology, plasticity and function. Prog. Neurobiol. 93, 522-548. doi: 10.1016/j. pneurobio.2011.03.002

Kent, B. A., and Brown, T. H. (2012). Dual functions of perirhinal cortex in fear conditioning. Hippocampus 22, 2068-2079. doi: 10.1002/hipo.22058

Kholodar-Smith, D. B., Allen, T. A., and Brown, T. H. (2008). Fear conditioning to discontinuous auditory cues requires perirhinal cortical function. Behav. Neurosci. 122, 1178-1185. doi: 10.1037/a0012902

Kloosterman, F., Witter, M. P., and Van, H. T. (2003). Topographical and laminar organization of subicular projections to the parahippocampal region of the rat. J. Comp. Neurol. 455, 156-171. doi: 10.1002/cne. 10472

Koenigs, M., and Grafman, J. (2009). Posttraumatic stress disorder: the role of medial prefrontal cortex and amygdala. Neuroscientist 15, 540-548. doi: 10. $1177 / 1073858409333072$

Koike, H., Fukumoto, K., Iijima, M., and Chaki, S. (2013). Role of BDNF/TrkB signaling in antidepressant-like effects of a group II metabotropic glutamate receptor antagonist in animal models of depression. Behav. Brain Res. 238, 4852. doi: 10.1016/j.bbr.2012.10.023

LeDoux, J. (2007). The amygdala. Curr. Biol. 17, R868-R874. doi: 10.1016/j.cub. 2007.08.005

Li, N., He, X., Zhang, Y., Qi, X., Li, H., Zhu, X., et al. (2011). Brain-derived neurotrophic factor signalling mediates antidepressant effects of lamotrigine. Int. J. Neuropsychopharmacol. 14, 1091-1098. doi: 10.1017/s14611457100 01082

Lindquist, D. H., Jarrard, L. E., and Brown, T. H. (2004). Perirhinal cortex supports delay fear conditioning to rat ultrasonic social signals. J. Neurosci. 24, 36103617. doi: 10.1523/jneurosci.4839-03.2004

Mahan, A. L., and Ressler, K. J. (2012). Fear conditioning, synaptic plasticity and the amygdala: implications for posttraumatic stress disorder. Trends Neurosci. 35, 24-35. doi: 10.1016/j.tins.2011.06.007

Maren, S. (2001). Neurobiology of Pavlovian fear conditioning. Annu. Rev. Neurosci. 24, 897-931. doi: 10.1146/annurev.neuro.24.1.897

Matsumoto, T., Rauskolb, S., Polack, M., Klose, J., Kolbeck, R., Korte, M., et al. (2008). Biosynthesis and processing of endogenous BDNF: CNS neurons store and secrete BDNF, not pro-BDNF. Nat. Neurosci. 11, 131-133. doi: 10. 1038/nn2038

McIntyre, D. C., Kelly, M. E., and Staines, W. A. (1996). Efferent projections of the anterior perirhinal cortex in the rat. J. Comp. Neurol. 369, 302-318. doi: 10. 1002/(SICI) 1096-9861(19960527)369:2<302::AID-CNE10>3.0.CO;2-J

Meis, S., Endres, T., and Lessmann, V. (2012). Postsynaptic BDNF signalling regulates long-term potentiation at thalamo-amygdala afferents. J. Physiol. 590, 193-208. doi: 10.1113/jphysiol.2011.220434

Munoz, P. C., Aspe, M. A., Contreras, L. S., and Palacios, A. G. (2010). Correlations of recognition memory performance with expression and methylation of brainderived neurotrophic factor in rats. Biol. Res. 43, 251-258. doi: 10.4067/s071697602010000200013

Musumeci, G., Sciarretta, C., Rodriguez-Moreno, A., Al, B. M., Negrete-Diaz, V., Costanzi, M., et al. (2009). TrkB modulates fear learning and amygdalar synaptic plasticity by specific docking sites. J. Neurosci. 29, 10131-10143. doi: 10. 1523/JNEUROSCI.1707-09.2009

Otto, T., Cousens, G., and Herzog, C. (2000). Behavioral and neuropsychological foundations of olfactory fear conditioning. Behav. Brain Res. 110, 119-128. doi: 10.1016/s0166-4328(99)00190-4

Ou, L. C., and Gean, P. W. (2006). Regulation of amygdala-dependent learning by brain-derived neurotrophic factor is mediated by extracellular signal-regulated kinase and phosphatidylinositol-3-kinase. Neuropsychopharmacology 31, 287296. doi: $10.1038 /$ sj.npp. 1300830

Ou, L. C., Yeh, S. H., and Gean, P. W. (2010). Late expression of brain-derived neurotrophic factor in the amygdala is required for persistence of fear memory. Neurobiol. Learn. Mem. 93, 372-382. doi: 10.1016/j.nlm.2009.12.003

Pang, P. T., Teng, H. K., Zaitsev, E., Woo, N. T., Sakata, K., Zhen, S., et al. (2004). Cleavage of proBDNF by tPA/plasmin is essential for long-term hippocampal plasticity. Science 306, 487-491. doi: 10.1126/science.1100135

Pape, H. C., and Pare, D. (2010). Plastic synaptic networks of the amygdala for the acquisition, expression and extinction of conditioned fear. Physiol. Rev. 90, 419463. doi: 10.1152/physrev.00037.2009

Paxinos, G., and Watson, C. (1997). The Rat Brain in Stereotaxic Coordinates. San Diego: Academic Press.

Pikkarainen, M., and Pitkanen, A. (2001). Projections from the lateral, basal and accessory basal nuclei of the amygdala to the perirhinal and postrhinal cortices in rat. Cereb. Cortex 11, 1064-1082. doi: 10.1093/cercor/11.11. 1064

Psotta, L., Lessmann, V., and Endres, T. (2013). Impaired fear extinction learning in adult heterozygous BDNF knock-out mice. Neurobiol. Learn. Mem. 103, 34-38. doi: 10.1016/j.nlm.2013.03.003

Rattiner, L. M., Davis, M., French, C. T., and Ressler, K. J. (2004a). Brain-derived neurotrophic factor and tyrosine kinase receptor B involvement in amygdala- 
dependent fear conditioning. J. Neurosci. 24, 4796-4806. doi: 10.1523/jneurosci. 5654-03.2004

Rattiner, L. M., Davis, M., and Ressler, K. J. (2004b). Differential regulation of brain-derived neurotrophic factor transcripts during the consolidation of fear learning. Learn. Mem. 11, 727-731. doi: 10.1101/lm.83304

Rattiner, L. M., Davis, M., and Ressler, K. J. (2005). Brain-derived neurotrophic factor in amygdala-dependent learning. Neuroscientist 11, 323-333. doi: 10. $1177 / 1073858404272255$

Rogan, M. T., Staubli, U. V., and LeDoux, J. (1997). Fear conditioning induces associative long-term potentiation in the amygdala. Nature 390, 604-607. doi: 10. $1038 / 37601$

Sacchetti, B., Lorenzini, C. A., Baldi, E., Tassoni, G., and Bucherelli, C. (1999). Auditory thalamus, dorsal hippocampus, basolateral amygdala and perirhinal cortex role in the consolidation of conditioned freezing to context and to acoustic conditioned stimulus in the rat. J. Neurosci. 19, 9570-9578.

Schulz, B., Fendt, M., Richardson, R., and Schnitzler, H. U. (2004). Temporary inactivation of the perirhinal cortex by muscimol injections block acquisition and expression of fear-potentiated startle. Eur. J. Neurosci. 19, 713-720. doi: 10. $1111 / j .1460-9568.2004 .03180 . x$

Sierra-Mercado, D., Padilla-Coreano, N., and Quirk, G. J. (2011). Dissociable roles of prelimbic and infralimbic cortices, ventral hippocampus and basolateral amygdala in the expression and extinction of conditioned fear. Neuropsychopharmacology 36, 529-538. doi: 10.1038/npp.2010.184

Sigurdsson, T., Doyere, V., Cain, C. K., and Ledoux, J. E. (2007). Long-term potentiation in the amygdala: a cellular mechanism of fear learning and memory. Neuropharmacology 52, 215-227. doi: 10.1016/j.neuropharm.2006.06.022

Suzuki, W. A. (1996). The anatomy, physiology and functions of the perirhinal cortex. Curr. Opin. Neurobiol. 6, 179-186. doi: 10.1016/s0959-4388(96) 80071-7
Suzuki, K., Maekawa, F., Suzuki, S., Nakamori, T., Sugiyama, H., Kanamatsu, T., et al. (2012). Elevated expression of brain-derived neurotrophic factor facilitates visual imprinting in chicks. J. Neurochem. 123, 800-810. doi: 10.1111/jnc.12039 Walker, D., Yang, Y., Ratti, E., Corsi, M., Trist, D., and Davis, M. (2009). Differential effects of the CRF-R1 antagonist GSK876008 on fear-potentiated, light- and CRF-enhanced startle suggest preferential involvement in sustained vs phasic threat responses. Neuropsychopharmacology 34, 1533-1542. doi: 10.1038/npp. 2008.210

Wetsel, W. C., Rodriguiz, R. M., Guillemot, J., Rousselet, E., Essalmani, R., Kim, I. H., et al. (2013). Disruption of the expression of the proprotein convertase PC7 reduces BDNF production and affects learning and memory in mice. Proc. Natl. Acad. Sci. U S A 110, 17362-17367. doi: 10.1073/pnas.1314698110

Conflict of Interest Statement: The authors declare that the research was conducted in the absence of any commercial or financial relationships that could be construed as a potential conflict of interest.

Received: 04 September 2013; accepted: 02 December 2013; published online: 17 December 2013

Citation: Schulz-Klaus B, Lessmann V and Endres T (2013) BDNF-dependent consolidation of fear memories in the perirhinal cortex. Front. Behav. Neurosci. 7:205. doi: 10.3389/fnbeh.2013.00205

This article was submitted to the journal Frontiers in Behavioral Neuroscience.

Copyright $(02013$ Schulz-Klaus, Lessmann and Endres. This is an open-access article distributed under the terms of the Creative Commons Attribution License (CC BY). The use, distribution or reproduction in other forums is permitted, provided the original author(s) or licensor are credited and that the original publication in this journal is cited, in accordance with accepted academic practice. No use, distribution or reproduction is permitted which does not comply with these terms. 